\title{
Desarrollo local: Hacia una nueva forma de desarrollo nacional y centroamericano
}

Alberto Enríquez Villacorta

\section{Introducción}

Cuando la Fundación Nacional para el Desarrollo (FUNDE) nace en 1992, su diseño contemplaba dos grandes áreas de trabajo: Desarrollo Nacional y Desarrollo Regional/Local.

Esto obedecía al propósito de aportar propuestas al desarrollo del país en lo tocante a las políticas macro económicas y sectoriales, por un lado, $y$, por otro, a nivel de los municipios y las regiones.

En aquel momento, recién terminado el conflicto armado y firmados los Acuerdos de Paz, la FUNDE planteaba la necesidad de buscar opciones de desarrollo para las localidades, ya que era evidente que al terminar la guerra muchos municipios y zonas del territorio nacional habian quedado devastados. Era el caso de muchas partes de la zona norte y de departamentos como San Vicente.

Por eso, la FUNDE inicia su trabajo local justamente en Chalatenango y San Vicente, más concretamente, en el nororiente de Chalatenango y en el municipio de Tecoluca.

Pero la FUNDE no tenía, por razones obvias, un planteamiento ni un enfoque sobre desarrollo local. Más aún, ni siquiera sobre desarro- 
llo o desarrollo sustentable. Lo que tenía entonces eran tres constataciones:

- Con los Acuerdos de Paz, el país entraba en una nueva etapa de su bistoria. Se habian cambiado las reglas del juego politico. Abora se podía iniciar la construcción democrática que a su vez pondría las condiciones para avanzar hacia un nuevo desarrollo, un desarrollo sustentable.

- Por ello, en el país urgían propuestas de vías de desarrollo que tomaran en cuenta a sectores mayoritarios excluidos históricamente de decisiones y beneficios

- No sólo existían sectores sociales excluidos, sino también territorios excluidos, aunque muchos de ellos con una base y experiencia organizativas muy fuertes.

Los Acuerdos de Paz no habían tocado las estructuras económicas del país. Como señala Salvador Samayoa, "tomados en conjunto, los protagonistas del arreglo negociado entendían bien que la pobreza y la injusticia social formaban parte de las entreveradas raíces del conflicto, pero también entendían que la negociación de la política económica, además de inviable, era un arma de dos filos” (Samayoa, 663).

Avanzar hacia un desarrollo sustentable sería, pues, uno de los desafíos de la transición que se abría en 1992. Esto implicaba, no sólo la construcción de propuestas, sino profundas transformaciones en el Estado, la entrada de la sociedad civil y de los gobiernos locales en la esfera de las decisiones y la creación de una nueva institucionalidad nacional y municipal que le diera sostenibilidad a los esfuerzos. Esta nueva institucionalidad debería abarcar a todos los actores del desarrollo: Estado, sociedad civil y sector privado.

En ese horizonte se situaba la FUNDE, como un centro de investigación y reflexión, de construcción de propuestas nuevas y de incidencia en las políticas de desarrollo del país.

La intuición llevó a concebir, como un área estratégica del desarrollo, el desarrollo local y regional. Lo que señalaba la FUNDE que el desarrollo en el país debería construirse de arriba hacia abajo y de abajo hacia arriba, simultáneamente. Que nadie debería quedar fuera de este esfuerzo, ni en términos sociales, ni en términos territoriales. 
Sin formularlo, entonces, de una manera precisa, la FUNDE postulaba que un desarrollo sustentable exigía la inclusión de todos los actores y agentes del desarrollo y de todas las localidades y regiones.

Hoy estamos a 10 años de la firma de los Acuerdos de Paz en Chapultepec, de vida, esfuerzo y trabajo de nuestra fundación y todavía a la transición le hacen falta soportes económicos y sociales más sólidos. Todavía "está pendiente un cambio histórico en la estructura económica de este pequeño país. En El Salvador de la posguerra, se han ensanchado considerablemente las capas medias y mucha gente ha mejorado su situación económica, pero también se ha ensanchado la franja social de la pobreza y se ha profundizado la tendencia a la concentración de capitales, tal vez hasta niveles sin precedentes". (Samayoa 663). Es decir se mantienen las raíces generadoras de la pobreza, la desigualdad y la marginación.

Más aún, a pesar de algunos esfuerzos que se han hecho por diversos actores sociales, todavía el país no cuenta con una visión y una estrategia de desarrollo sustentable, es decir, que sea humano, incluyente y que produzca de manera creciente y sostenida una mejora en las condiciones y calidad de vida de la mayoría de la población.

Por todo esto, vale la pena, aunque sea de manera muy resumida, hacer una reflexión, no sólo de lo que hemos hecho desde la FUNDE en materia de desarrollo regional y local, sino de cómo lo hemos hecho. $\mathrm{Y}$ compartir esto con aquellos y aquellas que han sido compañeros de camino, socios en el emprendimiento y que, como la FUNDE, continúan tenazmente, tesoneramente, tercamente agarrándose hasta de la rama más pequeña de esperanza, en la búsqueda de rutas, veredas y caminos que lleven a nuestro país hacia un desarrollo sustentable que sea fruto y generador de una vigorosa y amplia democracia.

\section{Construyendo un enfoque transformador: teoría y práctica}

Desde sus inicios, la FUNDE se pone como desafío contribuir a construir en El Salvador un enfoque de desarrollo. Para ello comienza combinando varias dimensiones, que luego serán los componentes de su metodología institucional.

La FUNDE no pretendía ser una empresa consultora o vendedora de servicios, pues esto haría que su quehacer estuviera determinado por el mercado y no permitiría desarrollar una agenda y planes pro- 
pios, construidos desde un espíritu de solidaridad y en función de buscar soluciones a los grandes desafíos del desarrollo y, en este caso, del desarrollo local.

Tampoco quería ser un centro que, por una parte consigue dinero y por otra consultores para hacer trabajos específicos, que es también una manera válida de hacer las cosas. La aspiración de la FUNDE era y sigue siendo, generar un nuevo pensamiento, asumir y apropiarse de los principales temas del desarrollo, contribuyendo a su análisis y debate, construir propuestas que incidan en las políticas de nacionales y locales de desarrollo y comprometerse con esas propuestas y con los actores.

Por eso, está en su misión y visión promover los debates de ideas, enfoques y propuestas, que no son para nosotros asuntos aislados o eventos de publicidad, sino que son eslabones, son momentos para poner nuestras propuestas sobre la mesa, contrastarlas con otras, escuchar, tomar nota y reflexionar.

Esa era la institución que queríamos hacer. Esa es la institución que a lo largo de diez años hemos tratado de hacer. Esa es nuestra forma propia de hacer institución.

Por eso, el área de desarrollo regional/local al igual que las otras áreas, se ha venido modelando al calor de los hallazgos. No nació pre definida. A lo largo de estos 10 años, ha pasado por diversos momentos y formas de organizarse al interior de la FUNDE y de aportar a los actores del desarrollo local.

Los principales componentes en ese forjamiento han sido:

- El acompañamiento de esfuerzos y procesos concretos de desarrollo local. Esto ha supuesto compartir con actores y procesos y establecer con ellos un diálogo y debate amplio, franco y directo.

- La investigación y el estudio con un propósito concreto: construir propuestas. Esto nos ha llevado a tejer una metodología que incluye de manera medular la dimensión propositiva, que incorpora la participación de los actores como algo inherente, y que conduce, a conocer pensadores, expertos y a entrar simultáneamente a dos tipos de debate: el debate académico y el debate político. El debate con los protagonistas del desarrollo local y con quienes toman de- 
cisiones y el debate con aquellos que contribuyen a analizarlo, a pensarlo, a generar pensamiento y teoría a partir de él y de cara a enriquecerlo. Y esto no sólo a nivel nacional, sino también centroamericano e internacional.

- La incidencia en las políticas públicas relacionadas con el desarrollo, sean éstas nacionales o locales. Desde los primeros intentos, la FUNDE comprendió que la incidencia sobre aquellos centros que toman las decisiones no puede ser una tarea ni sólo ni principalmente de la institución, sino de los actores del desarrollo local según el tema. La FUNDE, por eso, define su papel como acompañar, facilitar, apoyar y complementar esos esfuerzos de los diferentes agentes del desarrollo para incidir en la generación de políticas públicas nacionales y locales.

- La reflexión y análisis del equipo FUNDE. Aquí hablamos de algo muy profundo y difícil en cualquier organización o empresa: la construcción de equipo. Han sido muchos y sostenidos los esfuerzos por promover una reflexión y un análisis que ayuden a hacer equipo, a actuar como equipo. Pero no un equipo con pensamiento y práctica uniformes y mecánicos. Nada más alejado del desarrollo local y del espíritu de la FUNDE. El propósito ha sido formar un equipo que promueva la creatividad, la innovación y diversidad, que las aproveche y que las ponga en función de un esfuerzo institucional y nacional.

- La sistematización de pensamiento y experiencias, que se expresa en conferencias, artículos, Alternativas para el desarrollo, Avances de Investigación, Cuadernos de Análisis y Propuestas, libros, etc. y que producen siempre una rica y fecunda retroalimentación.

Combinando estos elementos, por supuesto, no sin problemas y conflictos y de manera imperfecta, después de los primeros 4 años, hacia 1996, habíamos arribado a tres primeras y grandes conclusiones básicas sobre el desarrollo local, que planteadas ahora suenan a verdades de Perogrullo, pero que para nosotros significaron meses y años de búsqueda, de investigaciones, de descubrimiento de municipios y localidades. 
- El desarrollo local y regional es un proceso de largo plazo

- Se trata de un proceso de CONCERTACIÓN de los diferentes actores dentro de un territorio concreto.

- Impulsar en El Salvador el desarrollo local y regional exige construir un ENFOQUE TRANSFORMADOR y esto no es labrar una definición sacada de libros o tejida a base de citas de diferentes autores. Se trata de "enfoque" y esto supone pensamiento y teoría. Pero se trata también de que sea "transformador" y esto supone conexión con la realidad y aterrizaje en la misma. Supone partir constantemente de esa realidad y volver sobre ella para contribuir a su modificación en la dirección del desarrollo. Supone análisis de esa realidad en diálogo con quienes la van modificando o pelean por mantenerla así como está.

\section{Desarrollo local un asunto del país y un factor clave del desarrollo nacional}

En esa lógica y sobre esas primeras piedras, la FUNDE ha venido elaborando su concepción y pensamiento sobre el desarrollo local y aportando a un enfoque del país. Es más, muchas de las características de dicho enfoque coinciden actualmente con las de otras instituciones que no sólo son distintas a la FUNDE, sino trabajan en contextos diferentes en América Latina, como el CLAEH en Uruguay, para mencionar sólo una de ellas.

Partiendo de ellas, podemos avanzar que el desarrollo local:

- Es un proceso de concertación entre los agentes - sectores y fuerzas- que interactúan en un territorio determinado,

- para impulsar con la participación permanente, creadora y responsable de ciudadanos y ciudadanas,

- un proyecto común de desarrollo,

- que incluye la generación de crecimiento económico, equidad, cambio social y cultural, sustentabilidad ecológica, enfoque de género, calidad y equilibrio espacial y territorial.

- con el fin de: elevar la calidad de vida de cada familia, ciudadano y ciudadana que vive en ese territorio contribuir al desarrollo del país y enfrentar adecuadamente los retos de la globalización y las transformaciones de la economía internacional. 
Esto implica:

- Una visión de mediano y largo plazo, que establezca el punto de llegada y el horizonte que determinan y dan sentido a las acciones del corto plazo y que permite avanzar de manera gradual.

- La concertación de los agentes locales con agentes regionales, nacionales e internacionales.

- La construcción de un nuevo Estado democrático y descentralizado,

- Una nueva manera de comprender y construir el país. Por una parte, se hace visible el territorio completo, todas sus regiones, municipios y comunidades, No sólo como "problemas", o como "fuentes de diversas demandas", sino también y principalmente, como sujetos y generadores de democracia y desarrollo.

- El reconocimiento de que la realidad es diversa. Se recupera el valor de las particularidades, potencialidades e identidades territoriales. El desarrollo local se vuelve un instrumento necesario en la gestión de la diferencia. Los procesos regionales y locales, con sus diferencias, pueden y deben ser motor del desarrollo nacional.

- Que los municipios sean concebidos como fuentes de procesos y recursos que, si se generan las condiciones apropiadas, pueden contribuir al desarrollo nacional.

\section{Desarrollo Local: una crítica a las políticas del gobierno. El desarrollo no es un producto de importación}

El desarrollo local, así entendido entra en contradicción con la concepción del gobierno actual según la cual el desarrollo viene de afuera y es un producto de importación y que se revela a través de sus dos grandes políticas económicas:

- Política comercial a partir de una irrestricta apertura de la economía para atraer inversiones extranjeras sin mayores criterios ni condiciones

- Remesas de los salvadoreños y salvadoreñas en Estados Unidos, que deben mantenerse - esto, por supuesto, no se dice- asegurando en el país las condiciones para su permanente expulsión. 
Partiendo de dicha concepción y de esas políticas, no es necesario el diseño e implementación de estrategias que fortalezcan la planta productiva del país, que articulen el sector productivo con el financiero, que abran paso y den soporte a dinámicas de desarrollo económico local.

En ese marco, se entiende perfectamente por qué el gobierno detuvo la puesta en marcha de la Estrategia Nacional de Desarrollo Local (ENDL) propuesta por el Grupo Consultivo y aprobada por el Presidente de la República en diciembre de 1999.

Desarrollo local implicaría, en la visión planteada, no el rechazo a los Tratados de Libre Comercio ni tampoco los esfuerzos del país para vincular lo más posible a los salvadoreños y salvadoreñas en el exterior con las dinámicas de desarrollo.

Lo que implicaría es poner en el centro de la política económica una estrategia que apunte y permita reducir las desigualdades sociales y los desequilibrios territoriales. Esto es, una estrategia para elevar la productividad nacional, para fortalecer la planta productiva del país, para generar dinámicas de desarrollo económico en los distintos municipios y regiones del país, para crear condiciones que disminuyan la expulsión de salvadoreños y salvadoreñas.

Y no se puede pasar a ello si antes no se toma una decisión política fundamental: que los actores locales, gobiernos municipales, sociedad civil local, pequeños, medianos y grandes productores locales, pasen a formar parte del sujeto del desarrollo y participen en las decisiones estratégicas que marcan el rumbo del país. En otras palabras, si no se pasa a niveles superiores de democracia.

\section{Desarrollo local y transformación del Estado: la necesidad de la descentralización}

La FUNDE llegó al tema de la descentralización del Estado a través del desarrollo local.

De lo anteriormente planteado, se concluye que un factor clave para promover el desarrollo local es la descentralización del Estado, entendida como proceso ordenado y progresivo de transferencias de competencias, responsabilidades, poder de decisión y recursos desde el gobierno central a las entidades estatales subnacionales, así como la 
apertura de éstas a la participación activa de la sociedad civil. Incluye, en consecuencia, la construcción de todas las capacidades necesarias en las entidades estatales subnacionales.

La descentralización del Estado consiste, esencialmente, en aproximar la gestión pública a la ciudadanía. La vigencia de las políticas de descentralización en el mundo actual se sustenta, justamente, en la necesidad de fortalecer la gobernabilidad democrática, mediante el establecimiento de una relación más directa, participativa y transparente entre la ciudadanía y sus representantes.

Se espera, además, que la descentralización contribuya a volver más eficiente al Estado, disminuyendo gastos innecesarios que se generan como producto de la excesiva burocracia.

La descentralización implica, por lo tanto, una reforma democrática del Estado, orientada a superar los esquemas tradicionales de concentración de poder, para pasar a un sistema complejo de instancias interrelacionadas a través de una complementación cooperativa.

En un sistema descentralizado, el poder, las competencias y los recursos que corresponden a cada una de sus instancias se distribuyen de modo tal que las decisiones y las acciones públicas se adoptan y se ejecutan en el lugar que permite una relación más directa y trasparente con la ciudadanía.

La descentralización debe, además, generar profundos cambios, tanto en la institucionalidad del gobierno nacional, como en la de los gobiernos subnacionales.

Finalmente, descentralizar el Estado no es sinónimo de debilitarlo, ni adelgazarlo. Todo lo contrario, debe llevar a un Estado vigoroso, con capacidad para cumplir su misión.

\section{Desarrollo local, factor de la integración centroamericana y la gestión de la globalización.}

Así como señalamos que el desarrollo local es una nueva forma de leer y hacer el país, de igual manera, es una nueva forma de leer y hacer Centroamérica.

Hay que comprender que el desarrollo local ha estado ausente en la mayoría de planteamientos y esfuerzos de integración regional. 
Pero su ausencia no equivale a la falta de una simple "pieza". Lo que falta es un componente que cambiaría la visión y con ella el quehacer de la integración centroamericana. La razón es bastante sencilla, el desarrollo local como factor de la construcción centroamericana nos llevaría a:

- Reconocer que un propósito estratégico de la integración es la reducción de los desequilibrios territoriales.

- Recuperar lo específico de cada país y cada territorio, toda la riqueza de la diversidad, pero poniéndola a jugar en favor de la construcción de una unidad: la diversidad en la unidad.

- Incorporar como parte del sujeto de la construcción regional a todos los actores locales.

- Los municipios y micro regiones como lugares y centros de construcción regional, recordando a Tocqueville cuando afirma que en los municipios está el corazón de la democracia.

- Tomar en cuenta que la creación de una base productiva más sólida y más amplia, demanda sin duda, un rol fundamental de los municipios, de los espacios locales.

- Comprender que lo anterior exige la descentralización de los Estados, pues un municipio y una municipalidad necesitan poder y autonomía para jugar en estos procesos. No es el municipio ni la municipalidad de hoy los que pueden aportar. Son un nuevo municipio y una nueva municipalidad en el marco de un Estado transformado.

- Articular espacios regionales para enfrentar y resolver problemas estratégicos y descentralizar competencias y recursos hacia los municipios son dos caras de una misma moneda. Sin ello ni las municipalidades ni los municipios podrán convertirse en actores reales.

- Incorporar y aplicar el principio de proximidad. La mayor proximidad al ciudadano es lo que permite al Estado una mejor forma, más eficiente, oportuna y eficaz de abordar y resolver problemas vitales.

Con una visión y un planteamiento que incorpore el desarrollo local, nos estaríamos obligando, en consecuencia, a re pensar todo el proceso y todo el sistema de la integración centroamericana. Estaríamos abriendo las puertas a una etapa nueva, que recogiendo la expe- 
riencia acumulada -esto es indispensable- debe transformar, en primer lugar, el sujeto mismo de la integración. Y no es una simple ampliación, no es un problema de número. Es un problema de visión, de óptica, de lógica y de ruta.

Obviamente, esto requiere de voluntad política de aquellos que actualmente tienen el poder para tomar decisiones. La entrada en la escena de la construcción regional de los gobiernos locales, de la sociedad civil local, de los pequeños y medianos empresarios y comerciantes locales al circuito donde se toman las decisiones, para involucrarse en ellas, cambiaría sustantivamente la agenda de la integración centroamericana, su lógica interna y las formas de llevarla adelante.

Esto supone entender de una vez por todas, que integración centroamericana no es sólo una integración de los gobiernos, ni siquiera de gobiernos, grandes empresas y algunos sectores económicos fuertes. Es una integración de todos los actores y de todos los territorios. Requiere de una visión que busque hacer competitivos todos los territorios.

Más aún, ésta debería ser la óptica desde la que los centroamericanos y centroamericanas, analicemos y juguemos en otro tipo de proyectos como los Tratados de Libre Comercio y el Plan Puebla Panamá (PPP). Es decir, asegurar que los tratados, acuerdos y proyectos internacionales que suscribamos, nos permitan avanzar y fortalecer ese gran proyecto territorial, esa gran construcción comunitaria que se llama Centroamérica.

\section{Globalicemos lo local y hagamos local la globalización}

No es un juego de palabras. En la FUNDE entramos al Siglo XXI convencidos de que el desarrollo, si es genuino, deberá articular lo global y lo local. Tratar de anular una de las dos dimensiones equivale a castrar el desarrollo o renunciar a él.

A pesar de los múltiples y encendidos debates en torno a la globalización y de las diferencias en los análisis e interpretaciones del fenómeno, es indiscutible que estamos abriendo el Siglo XXI en 'medio de un amplio proceso de globalización, de interconexión entre economías, sociedades y culturas que afirmándose sobre la nueva y cambiante infraestructura tecnológica, va transformando nuestras formas de producir, consumir, gestionar, informar y pensar. 
Por eso, muchos pensadores europeos y latinoamericanos afirman que la globalización no es, sólo ni principalmente, económica. Es también social, política, tecnológica y cultural. Es, como el desarrollo mismo, multidimensional y va provocando la transformación del tiempo y el espacio en nuestras vidas. Sucesos muy lejanos, sean éstos económicos o políticos, sociales, religiosos o culturales, nos afectan más directamente que nunca, ya sea que vivamos en un municipio de los Estados Unidos, Francia o Alemania o de cualquier país africano o centroamericano.

De acuerdo a lo anterior, lo global no excluye lo local, sino lo presupone y lo complementa y lo local no es ajeno a lo global, ni puede ignorarlo. La coexistencia de dinámicas que tienden a la mundialización con otras que acentúan las especificidades y por tanto, las diversidades es hoy más real que nunca.

El desarrollo local no es pensable ni posible si no toma en cuenta la racionalidad globalizadora de los mercados o la lógica mundial de la producción de tecnologías.

Pero tampoco es viable si no parte de las identidades concretas - singulares por definición-, que lograrán que ese proceso de desarrollo esté realmente habitado por aquellos hombres y mujeres, niños y niñas, ancianas y ancianos de carne y hueso, que van tejiendo sus existencias en territorios específicos. Se trata, entonces, de encontrar la construcción de una relación dinámica y creativa entre lo local y lo global, que genere sinergia social y económica, política y cultural.

En el marco y el horizonte de las consideraciones anteriores, el desarrollo local no es algo "de adorno" o secundario, para un país que pretenda consolidar la democracia, construir un desarrollo sustentable y enfrentar adecuadamente el proceso de globalización.

Esto subraya la urgente necesidad que tiene cada uno de nuestros países centroamericanos de un proyecto de nación, que marque el "desde dónde" y el "cómo" se irán incorporando al proceso de globalización, aprovechando de la mejor manera las oportunidades y enfrentando creadoramente las amenazas.

En este proyecto, que debería incluir de manera armónica factores económicos, territoriales, ambientales, políticos, éticos, sociales y culturales y construirse con la más amplia participación de los diversos 
actores y fuerzas sociales, el desarrollo local debería ser una pieza fundamental. Esto mismo vale también para la Integración Centroamericana.

\section{La lógica de nuestra agenda actual}

A partir de todo lo anterior, se explica la agenda actual de la FUNDE en el terreno del desarrollo regional-local y la descentralización del Estado.

El desarrollo local como lo bemos planteado, es muy amplio y complejo. La FUNDE no pretende ni podría abarcarlo todo.

Pero dado que la concertación y participación de los actores es una condición "sine qua non" del desarrollo local, ese es nuestro Programa I. En él hacemos énfasis en cinco ejes:

- Institucionalización de la participación ciudadana

- Participación de las Mujeres, la Niñez y adolescencia y los salvadoreños y salvadoreñas en el exterior.

- Conformación de Alianzas Multisectoriales

- Asociación de municipios y construcción de regiones de desarrollo.

El desarrollo local es multidimensional, pero la dimensión económica adquiere una importancia especial. Nuestro Programa II es, por ello, Desarrollo Económico Local. Refleja una priorización de dicha dimensión. Y tiene como ejes:

- Municipalidad como agente del desarrollo económico local

- Iniciativas locales para generación de empleo e innovaciones tecnológicas

- Financiamiento del desarrollo local

- Potencialidades competitivas territoriales

- Participación de mujeres en el desarrollo económico local

Finalmente, es obvio que sin políticas nacionales no hay desarrollo local posible. Nuestro Programa III se centra en esto y subraya cuatro ejes: 
- Descentralización del Estado

- Ordenamiento territorial

- Financiamiento del desarrollo local

- Integración Centroamericana:

Son estos tres programas con sus ejes fundamentales los que guían la investigación, construcción de propuestas y esfuerzos de incidencia de la FUNDE en el Área de Desarrollo Regional - Local.

Complementa esta agenda un esfuerzo estratégico por la formación y capacitación de los actores, que parte de la convicción y la constatación diaria de que el desarrollo local y regional necesita gestores y gestoras que deben prepararse, profesionalizarse y aún especializarse.

Por ello, la FUNDE actualmente combina cursos y talleres de tipo municipal y micro regional con cursos nacionales especializados como Gerencia Municipal y Gestión de Riesgos, un Diplomado que es el Curso Nacional Especializado de "Gestión del Desarrollo Local". Estos tres se impulsan en alianza con la Fundación Salvadoreña de Apoyo Integral (FUSAI). También este año se inició, por iniciativa de la FUNDE, la Maestría en Desarrollo Local, que es un esfuerzo conjunto con la Universidad Centroamericana José Simeón Cañas (UCA), el CLAEH y la Universidad Católica de Uruguay y la Diputación de Barcelona.

\section{Construyendo alianzas estratégicas}

Si un planteamiento central en nuestro concepto de desarrollo sustentable y en particular de desarrollo regional-local es la necesidad de asociarse, de sumar esfuerzos, de generar sinergias virtuosas por todas partes, no seríamos coherentes si la FUNDE no hiciera lo propio. Sin entrar en detalles, queremos señalar algunas experiencias en diversos planos:

A nivel nacional la FUNDE es fundadora y miembro de la Red para el Desarrollo Local (RDL) y ha tenido el honor y la responsabilidad de ejercer su coordinación durante casi cuatro años. La RDL está integrada además por: la Fundación Salvadoreña de Desarrollo Integral (FUSAI), la Fundación Guillermo Manuel Ungo 
(FUNDAUNGO), el Sistema de Asesoría y Capacitación para el Desarrollo Local (SACDEL) y la Fundación (FUNDAMUNI)

A nivel Centroamericano, la FUNDE ha formado parte de un esfuerzo reciente que es la Conferencia Centroamericana sobre Descentralización y Desarrollo Local (CONFEDELCA), que lleva ya dos ediciones, una en El Salvador y otra en Guatemala. La CONFEDELCA es un espacio regional de debate, intercambio y construcción de vínculos y relaciones entre los diversos actores de los países centroamericanos del desarrollo local y la descentralización. La FUNDE actualmente juega el rol de Secretaría Técnica regional.

Desde dicho espacio, la FUNDE integra el Comité Organizador de la I Cumbre Latinoamericana de Desarrollo Local y Descentralización del Estado, que está programada para realizarse en Arequipa, Perú, en junio del 2003.

El Círculo Centroamericano de Aprendizaje en "Niñez y Desarrollo Local" ha sido otro esfuerzo que la FUNDE ba impulsado junto a instituciones internacionales como Save the Children y UNICEF $y$ centroamericanas como CALDH de Guatemala.

A nivel latinoamericano, la FUNDE es miembro de la Asociación Latinoamericana de Organismos de Promoción (ALOP) y forma parte activa de su Grupo de Trabajo en Desarrollo Local.

\section{Hacia un nuevo enfoque de la cooperación internacional}

Es obvio, a la luz de lo planteado, que la cooperación internacional tiene en el desarrollo local un campo para contribuir a generar en nuestro país - y en todos los países de Centroamérica-, condiciones democráticas, mayores niveles de gobernabilidad, un Estado de Derecho y bases para un desarrollo sustentable.

Pero dentro de la concepción de desarrollo local que la FUNDE ha venido construyendo y que hemos esbozado en este trabajo, esto tiene varias implicaciones:

- La cooperación debe ser vista e implementada, como un complemento que fortalece capacidades nacionales y locales, y jamás las sustituye. 
- Los actores y agencias de cooperación deben ser socios en esta empresa, sean sus contrapartes comunidades, Comités de Desarrollo Local, Gobiernos Municipales o instituciones ciudadanas.

Pero ese ser "socios" significa que asumen responsabilidad, más allá de lo estrictamente financiero. Por una parte, promoviendo también la cooperación técnica, profesional, cultural, etc. y, por otra abriendo o ampliando vínculos entre municipios, experiencias concretas, actores, sociedades y países.

- Se debe trabajar en base a reglas previamente pactadas y que aplican para ambas partes

- Dado que la empresa de la democracia y el desarrollo hoy, vinculan lo local con lo global, en el terreno global hay un campo de acción conjunta. La ciudadanía y los municipios de Sur y Norte, tenemos una responsabilidad de incidir en procesos globales e internacionales, que ofrezcan mejores oportunidades a lo local como ruta de construcción nacional.

Por ello, la FUNDE se ha venido esforzando para que en el campo del desarrollo local, la relación con la cooperación internacional:

-Fortalezca mutuamente nuestra visión del desarrollo local como campo de transformaciones democráticas y semillas de desarrollo sustentable y como espacio para establecer alianzas estratégicas internacionales

- Redoble nuestra voluntad y decisión de apostar en serio en esa dirección

- Amplíe, multiplique y vigorice nuestros vínculos, los de nuestras sociedades y nuestros países, profundizando aquello que es la base y palanca sobre lo que gira lo demás y debe caracterizar la relación entre nuestros pueblos: el respeto, el sentido de justicia y la solidaridad.

\section{Algunas reflexiones finales}

Quiero terminar haciendo una reflexión personal después de 10 años de trabajo en la FUNDE en los que básicamente he tenido dos responsabilidades: desarrollo regional-local e incidencia. 
Es muy difícil construir una institución de verdad, que sea parte de la sociedad y esté a su servicio. Y es más difícil si esta institución:

Se sitúa en el campo del desarrollo y quiere generar pensamiento, nuevos enfoques, en medio de una sociedad y un entorno inmediato donde en nombre de lo "concreto" y lo inmediato el pensamiento y la teoría son menospreciados. Y donde la academia está todavía muy lejos de la realidad.

Busca conectar la teoría con la práctica, con los actores de carne y hueso, con las apuestas y los intereses diversos y a veces encontrados y trata de facilitar la apertura de espacios, puentes y vasos comunicantes. Allí se entiende bien por qué Touraine dijo en Montevideo este año que lo qué más necesita el desarrollo en nuestros países son ingenieros de caminos y puentes, refiriéndose a la necesidad de comunicarse entre sectores y actores y a la necesidad de concertar

Mantiene una genuina autonomía de los partidos políticos, del gobierno y de los grupos económicos, que no logran desprenderse de una lógica de intolerancia y sometimiento

Recibe su mayor financiamiento de la cooperación internacional y trata de mantener también frente a ella, autonomía y un profundo respeto, venciendo las tentaciones de dejarse imponer agendas y lógicas - a veces por agencias internacionales, a veces por aquellas personas que las dirigen o representan-, bajo el ofrecimiento de fondos y apoyos de diverso tipo.

Pero todo esto vale la pena. Nuestros países necesitan con urgencia que la sociedad civil aporte a la construcción democrática y al impulso de un desarrollo sustentable desde una institucionalidad cada vez más amplia y diversa, cada vez más sólida y consistente, cada vez más propositiva y creadora.

En este marco, no se pueden celebrar los 10 años de la FUNDE sin hacer varios reconocimientos y agradecimientos:

A quienes fundaron la FUNDE en 1992, por su visión y su compromiso en aquel momento en que todo era incierto y no era fácil pre ver el futuro inmediato del país

A nuestros investigadores e investigadoras, técnicas y técnicos que han sido parte de nuestros equipos y a todo el personal de apoyo, que creen que hacer país, hacer desarrollo y hacer democracia implica co- 
nocimiento, alto nivel profesional, compromiso concreto y cotidiano y una ética incuestionable y que para hacer eso, vale la pena construir una institución, donde se vuelve tan importante aquella o aquel que investiga o asesora, como aquel o aquella que garantiza el soporte administrativo o el cuido de la oficina y los equipos de trabajo

A nuestros socios nacionales: SAPRIN, Red para el Desarrollo Local, CIDAR, Foro Agropecuario.

A nuestros socios centroamericanos e internacionales como el CID, el Foro Mundial de las Alternativas, ALOP, y muchas agencias de cooperación internacional, que han creído en nuestra apuesta y han jugado con nosotros, especialmente aquellos que se asocian al esfuerzo más allá del dinero y el financiamiento y lo hacen con profundo respeto y con espíritu crítico.

Y sobre todo a quienes nos demandan y nos impulsan: comunidades territoriales, gobiernos municipales, organizaciones sociales, otras instituciones, que nos han permitido adentrarnos en sus procesos, en sus esfuerzos, a quienes aportan a nuestras investigaciones y estudios, a quienes exigen calidad y excelencia en nuestros servicios, a quienes leen y critican nuestras publicaciones. Porque justamente en ellos encuentra la FUNDE su razón de ser y la fuente de energía para seguir su camino.

A todos y todas ellos gracias, porque han hecho posible una FUN$\mathrm{DE}$, que con debilidades y fallas, a través de aciertos y equivocaciones, se ha venido convirtiendo en un espacio institucional que permite y demanda, un compromiso con el forjamiento de un nuevo desarrollo de El Salvador y de Centroamérica

Es toda la experiencia acumulada en estos 10 años, la que hace que frente al complejo panorama que presentan el país y la región centroamericana, estemos optimistas, no como sinónimo de ilusos, porque nuestro optimismo tiene razones y asideros muy concretos que señalamos a lo largo de nuestra exposición:

procesos de desarrollo local y regional en marcha cambios y transformaciones que se viene incubando lentamente desde abajo a partir de los Acuerdos de Paz nuevas formas de gobernar que se abren paso en diversos municipios tres actores del cambio que se fortalecen: ciudadanía, gobiernos locales y pequeña y mediana empresa corrientes in- 
ternacionales y procesos similares en otros países de Centroamérica y el mundo.

Pero ese optimismo es la base, no para acomodarse, sino para continuar una lucha de largo aliento, con responsabilidad y pasión.

El desarrollo como lo entendemos en la FUNDE, demanda lo mejor de todos y todas nosotros. No sólo voluntad. También preparación y conocimientos. también ética y valores.

En la batalla por abrirle paso al desarrollo de El Salvador y Centroamérica, la razón debe conducir a la pasión, pero no suprimirla. La pasión debe estimular a la razón, pero no la enceguecerla ni nublarla.

En este $\mathrm{X}$ aniversario, el mensaje que queremos transmitir desde la FUNDE a los salvadoreños y salvadoreñas es la urgencia de hacer ese nuevo país que quedó apenas esbozado en los Acuerdos de Paz y con ellos comenzó a dar sus primeros pasos. Es posible hacerlo. Pero tenemos que hacerlo entre todos y todas.

Entre los desafíos del nuevo siglo se encuentra el desafío de imaginar las transformaciones que nuestro país necesita y que son posibles de concretar. Salgamos pues, como dice Carlos Fuentes, "a ganar la batalla cotidiana de una democracia con historia, una justicia con memoria y un

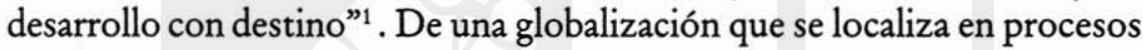
múltiples y diversos de desarrollo que incorpora la diversidad y lo específico. Y de un desarrollo local que se globaliza, para encontrar en los escenarios y tendencias mundiales nuevas oportunidades y espacios para el aporte propio y creativo.

NotA

1. Fuentes, Carlos: "Las dos caras de la Globalización". La Prensa Gráfica. San Salvador, El Salvador. Pág.46, 23 de marzo de 2002. 